\title{
Adults and children engaging with ePortfolios in an early childhood education setting
}

\section{Tracey Hooker}

\begin{abstract}
While common across the primary, secondary and tertiary sectors of education, ePortfolios are relatively new in the early childhood education sector, nationally and internationally. They are, however, becoming more widespread in Aotearoa New Zealand as a platform to present children's formative assessment documentation. There is very little documented evidence of the use of ePortfolios in early childhood education (ECE) and as such little is known about how they could impact on parent and whānau i engagement with their children's learning; teachers' formative assessment practices; how they contribute to children's learning journeys and indeed how children could use ePortfolios. This study located in Aotearoa New Zealand investigated the use of ePortfolios in an early childhood education setting and how teachers, parents, whānau and children engaged with them, in comparison to their engagement with paper- based portfolios.
\end{abstract}

The ECE setting involved in this research was using paper-based portfolios as artefacts to document children's development and learning over time, and had been doing so for several years prior to the research being undertaken. The setting had a history of robust documentation but struggled to find ways that enabled parents and whānau to contribute to this documentation in a written form. After a period of investigation into the use of paper-based portfolios, and their effectiveness in encouraging parents and whānau to contribute, ePortfolios were introduced. Accordingly this research presents a comparative study of paper-based portfolios and ePortfolios.

After the introduction of ePortfolios, significant changes were evident in the ways that parents, whānau and teachers engaged with the learning documentation contained in the ePortfolios. Changes were also evident in the teachers' formative assessment practices and in the ECE setting's community of practice, which at the onset of the research was just developing.

Consequently, the research underlined the importance of portfolios, in whatever format, as artefacts which encourage children, their families and teachers to revisit their learning-allowing for support and extension of the learning. This thesis presents these findings and discusses the implications for practice and policy.

\footnotetext{
${ }^{\mathrm{i}}$ Whānau means family in the language of the indigenous people of Aotearoa New Zealand - Māori. 